\title{
FLUXOS DE TRABALHO COM FERRAMENTAS BIM: APLICAÇÃO DE QUESTIONÁRIO ONLINE
}

\author{
FLUJOS DE TRABAJO CON HERRAMIENTAS BIM: APLICACION DE CUESTIONARIO ONLINE
}

WORKFLOWS WITH BIM TOOLS: AN ONLINE SURVEY

\author{
VENÂNCIO, RAONI \\ Dr., Professor de Arquitetura e Urbanismo da Universidade Federal de Campina Grande - raoni_vs@yahoo.com.br
}

\section{BRITO, DÉBORAH CECÍLIA TRIGUEIRO CUSTÓDIO DE

\author{
Graduanda em Arquitetura e Urbanismo da Universidade Federal de Campina Grande - deborah.c.brito@gmail.com
}

\begin{abstract}
RESUMO
O advento de softwares BIM como suporte ao projeto de arquitetura trouxe não só uma nova ferramenta de trabalho para o arquiteto, mas também um novo modo de projetar. Além das vantagens práticas trazidas pelo processo BIM, o uso desse tipo de ferramenta no projeto desafia procedimentos tradicionais no modo de ver e conceber, o que traz rebatimentos na prática projetual. Esse artigo apresenta parte de uma pesquisa que visa investigar os principais padrões de fluxos de trabalho com ferramentas BIM a partir da aplicação de questionários online com arquitetos, engenheiros e estudantes brasileiros. Os dados coletados são analisados com o uso de filtros, que ajudam a compreender melhor os resultados, enriquecendo a análise. Com base nas informações obtidas, o texto faz uma síntese dos principais fenômenos que podem apresentar algumas consequências potencialmente negativas no processo de projeto de arquitetura.

PALAVRAS-CHAVE: BIM; fluxos de trabalho; processo projetual.
\end{abstract}

\section{RESUMEN}

El advenimiento de software BIM como soporte al proyecto de arquitectura trajo no sólo una nueva herramienta de trabajo para el arquitecto, sino también un nuevo modo de concepción. Además de las ventajas prácticas traídas por el proceso BIM, el uso de este tipo de herramienta en el proyecto desafía procedimientos tradicionales en el modo de ver y concebir, lo que trae rebajas en la práctica proyectual. Este artículo busca investigar las principales tendencias y patrones de flujos de trabajo con herramientas BIM a partir de la aplicación de cuestionarios online con arquitectos, ingenieros e estudiantes brasileños. Los datos recolectados se analizan con el uso de filtros, que ayudan a comprender mejor los resultados, enriqueciendo el análisis. Con base en las informaciones obtenidas, el trabajo hace una síntesis de los principales fenómenos que pueden presentar algunas consecuencias potencialmente negativas en el proceso de proyecto de arquitectura. PALABRAS CLAVE: BIM; flujos de trabajo; proceso proyectual.

\section{ABSTRACT}

The emergence of BIM software as a support for the architectural design brought not only a new working tool to the architect, but also a new way of designing. In addition to the practical advantages of BIM processes, the use of BIM tools in the project challenges traditional procedures in the way we see and conceive and this may affect design practice. This article aims to investigate the main patterns of workflows with BIM tools from the application of online survey with architects, engineers and undergraduate students from Brazil. The data collected are analyzed using filters, which enhances the understanding of results, enriching the analysis. Based on the information obtained, the paper summarizes the main phenomena that may present some potentially negative consequences in the architectural design process.

KEYWORDS: BIM; workflows; design process. 


\section{INTRODUÇÃO}

A representação do objeto arquitetônico por meio de projeções ortogonais, além da finalidade meramente descritiva, que busca permitir a execução e compreensão do projeto, é também importante como instrumento de concepção para potencializar o processo reflexivo. O uso do desenho como instrumento de antecipação da realidade futura é tão antigo e tradicional que foi abordado por Leon Battista Alberti em seu tratado Da Re aedificatoria Libri Decem, de 1452:

Devo dizer que com frequência me ocorre conceber formas que, em princípio, me pareciam muito acertadas, mas que, uma vez desenhadas, revelavam erros gravíssimos, precisamente naquelas partes que mais me tinham dado prazer; tendo que voltar depois, de forma meditativa, a tudo o que tinha desenhado, e, medindo as proporções, reconhecia e deplorava minha negligência (ALBERTI, 1452 apud RAMOS, 2011).

A capacidade de antecipar a realidade futura de uma edificação imaginada é, de fato, inerente à prática projetual no campo da arquitetura. Ao longo do processo de concepção, o projetista conduz simulações mentais sobre diversos aspectos do projeto (DONN, 2014): fluxos de pessoas, alcance visual, vistas da edificação, relações espaciais, dentre inúmeros outros. Esse processo de reflexão em ação é possibilitado pela capacidade do projetista de representar suas ideias no papel e perceber, no objeto representado, potencialidades e limitações das soluções testadas (SCHÖN, 1983).

Arquitetos lidam com meios abstratos de representação para exprimir intenções, ideias e significado a seus projetos (AMBROSE, 2006). A planta, o corte e a fachada, assim como perspectivas isométricas, são abstrações do espaço arquitetônico. Por se tratarem de simplificações da realidade, o uso dessas representações no processo de concepção facilita o enquadramento da situação de projeto, ao permitir isolar determinadas informações de maneira mais compreensível para o tomador de decisões ${ }^{1}$.

$O$ desenvolvimento de ferramentas CAD trouxe inúmeros benefícios para a produção de desenhos (representação bidimensional). Além de fazer o processo de representação mais eficiente, por realizar o desenho técnico em ambiente virtual, novas ferramentas permitiram modificações de projeto que antes seriam contraproducentes em processos de desenho a instrumento. Entretanto, não há mudança significativa no processo de concepção do projeto. Os programas adotam a mesma lógica da prancheta, só que em ambiente digital: o desenhista insere informações geométricas bidimensionais (linhas, arcos, hachuras, etc.) para produzir desenhos técnicos. Dessa maneira, quando uma modificação é feita no projeto e provoca implicações no grupo de representações bidimensionais, deve-se alterar individualmente cada desenho.

Além disso, frequentemente o modelo do projeto é feito em outro software, o que torna ainda mais difícil manter a coerência do conjunto de representações do projeto. De fato, o único vínculo entre toda a documentação produzida ocorre somente na edificação imaginada pelo arquiteto. Dada a limitação de nossa capacidade de processar informações, não é rara a ocorrência de incongruências entre desenhos ou até de erros de concepção - o mesmo fenômeno observado por Alberti há mais de cinco séculos.

$O$ desenvolvimento de ferramentas Building Information Modeling (BIM) traz a possibilidade de mudar radicalmente o processo projetual e o ensino de arquitetura (AMBROSE, 2006). Isto porque no processo BIM, constrói-se o modelo virtual da edificação associando a ele diversas informações, não somente geométricas, mas especificações diversas sobre materiais, texturas, e todos os elementos do edifício. A partir do seccionamento no modelo geométrico, são geradas as representações tradicionais (plantas baixas, cortes, elevações), o que faz com que o conjunto seja coerente entre si: se há uma alteração no modelo, ela é automaticamente reproduzida nos desenhos. Em certa medida, o desenho se torna o fim do processo, não o começo².

Em comparação ao processo tradicional de representação, amplamente baseado em vistas ortogonais, a adoção do processo BIM permite uma antecipação sem precedentes da realidade futura da edificação. $O$ usuário pode antever a edificação nos mínimos detalhes, pois ela está sendo construída virtualmente. Dessa forma, muitos imprevistos que só seriam revelados na obra podem ser evitados, assim como também se pode supor que potenciais equívocos de projeto também podem ser observados e sanados ao longo do processo de modelagem, através da contínua visualização do modelo que está sendo construído.

As vantagens práticas da adoção do BIM são diversas. Muitas publicações trazem comparativos de eficiência entre o processo tradicional e do processo BIM, tanto em aspectos gerais (BRYDE et al., 2013), benefícios no canteiro de obras (FERNANDES, 2013), no acompanhamento do ciclo de vida do projeto (TALEBI, 2014) ou até na melhoria da qualidade de vida dos agentes da construção civil (TAKIM et al., 2013). Apesar das vantagens, são processos que desafiam procedimentos consolidados no modo de ver e conceber o projeto, com implicações consideráveis na prática e no ensino de arquitetura. 
Arquitetos e outros profissionais ligados ao design se acostumam a pensar o projeto a partir de abstrações simplificadas da realidade (plantas, cortes, elevações). O processo BIM, em oposição, envolve a construção virtual da edificação: "o modelo virtual é a coisa, assim como a representação da coisa" (AMBROSE, 2006). Isto faz com que ferramentas BIM sejam, em essência, antiabstração.

Lidar com essa natureza antiabstrata desse tipo de ferramenta pode ser um desafio no processo projetual de arquitetura. A quantidade de informações e definições de projeto que um modelo virtual exige é considerável e isso pode dificultar o uso dessas ferramentas em fases iniciais de projeto - mais suscetíveis a uma abordagem mais abstrata. Para representar o processo de maturação dos elementos do projeto, foi desenvolvido o conceito de LOD - Level of Development (nível de desenvolvimento) (AMERICAN INSTITUTE OF ARCHITECTS, 2008) que representa graus de completude dos vários elementos de uma edificação ao longo do processo de projeto ${ }^{3}$.

Apesar de útil na tentativa de representar um processo de maturação de projeto que ocorre de modo muito fluido, essa sistematização está pouco presente nos cursos de treinamento em ferramentas BIM, que normalmente se limitam aos recursos dos programas. Assim, estudantes e arquitetos que não tiveram acesso a uma formação mais especializada podem desenvolver práticas viciosas no uso desses recursos, 0 que pode ser danoso ao processo de concepção.

Esta pesquisa foi motivada pelo interesse pedagógico da aplicação de ferramentas BIM no ensino de arquitetura. Para se chegar a algum tipo de proposição mais clara nesse sentido, é necessário primeiramente ter noção sobre fluxos de trabalho BIM comumente usados no Brasil, entendendo-se 'fluxo de trabalho' como o conjunto de atividades, processos e ferramentas adotadas no projeto arquitetônico e que culminam no modelo BIM arquitetônico. Como as ferramentas BIM são bastante complexas, impedindo que se tenha um fluxo de trabalho único, a pesquisa busca identificar as principais tendências nesse campo.

Considerando que o uso desses programas ainda é claramente minoritário (tanto na prática profissional quanto na academia), verificou-se que o questionário online seria o método de coleta de informações com potencial para obtenção de uma boa amostra. Não são raras as pesquisas que adotam questionários online para compreender diferentes facetas do processo BIM, como barreiras para implementação da tecnologia (YAN, DAMIAN, 2008), sobre o valor percebido pela indústria de construção civil (BECERIK-GERBE, RICE, 2010), dentre outros enfoques. Contudo, as pesquisas geralmente se concentram na adoção da tecnologia BIM em alto nível profissional, sem avaliar possíveis dificuldades que usuários não inseridos nesse contexto podem ter na prática do projeto arquitetônico.

O objetivo geral deste artigo é, a partir da aplicação de questionários online, investigar as principais tendências referentes ao uso de ferramentas BIM por arquitetos, engenheiros civis e estudantes, notadamente no que diz respeito aos padrões de fluxos de trabalho.

\section{MÉTODO DE PESQUISA}

O procedimento metodológico adotado foi a aplicação de questionários online, por permitir um alcance em todo o território nacional. A elaboração do questionário se deu de acordo com os tópicos de interesse, com a abordagem dos seguintes temas:

- Características gerais da amostra: informações que caracterizam profissionalmente o participante;

- Prática de processos BIM: aborda o uso de ferramentas BIM ao longo do processo de projeto;

A fim de se obter uma amostra satisfatória e um alcance mais amplo em território nacional, o questionário foi hospedado na plataforma Google Forms que, além de ser um serviço fornecido gratuitamente, disponibiliza os resultados em forma de gráficos e de planilhas do Excel, o que torna possível a filtragem de respostas com relativa liberdade.

O instrumento foi composto ao todo por 24 perguntas, grande parte de natureza objetiva, mas com opção de complementação da informação. A duração média (estimada) para resposta foi de 12 minutos.

O questionário ficou aberto a respostas por 4 meses, tendo sido divulgado em diversos fóruns da comunidade BIM e enviado a vários cursos e grupos de pesquisa em Arquitetura e Urbanismo do Brasil. 


\section{ANÁLISE: DESCRIÇÃO DOS RESULTADOS}

\section{Características gerais da amostra}

Ao todo, foram obtidas 84 respostas válidas, com predominância de participantes da região Sudeste (45\%), com razoável proporção de participantes do Nordeste (20\%) e Sul (17\%) - Gráfico 1. Dentre os estados de origem dos respondentes, a maior ocorrência é do estado de São Paulo (36\%), seguido de Pernambuco $(11 \%)$ e Santa Catarina (7\%).

No que se refere à formação profissional e acadêmica (Gráfico 2A), verifica-se significativa participação de arquitetos e urbanistas (42\%) e estudantes (34\%), além de uma razoável participação de engenheiros civis $(17 \%)^{4}$. Dentre os participantes com graduação completa (Gráfico $2 \mathrm{~B}$ ), $42 \%$ se formaram há mais de 11 anos (42\%) e 44\% têm menos de quatro anos de graduação.

Gráfico 1: Caracterização da amostra: região e estado.

Em que região do Brasil você vive?

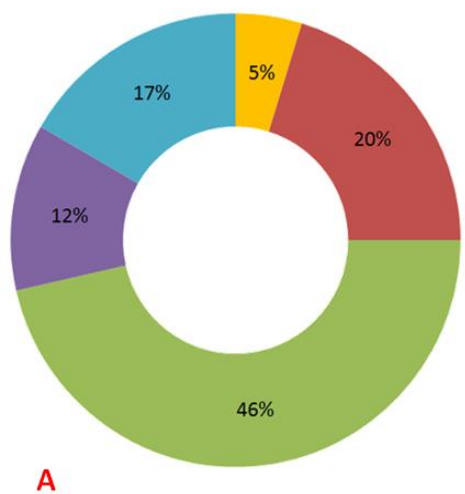

Em que estado você vive?

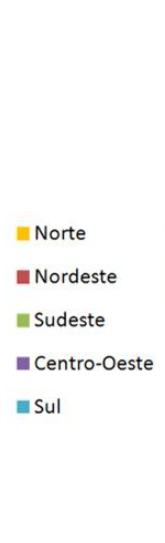

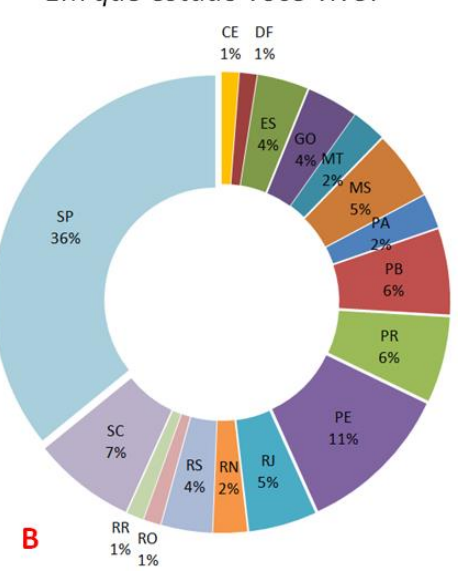

Fonte: Acervo dos autores.

Gráfico 2: Formação: tipo de formação e anos de formado

Qual sua formação profissional?

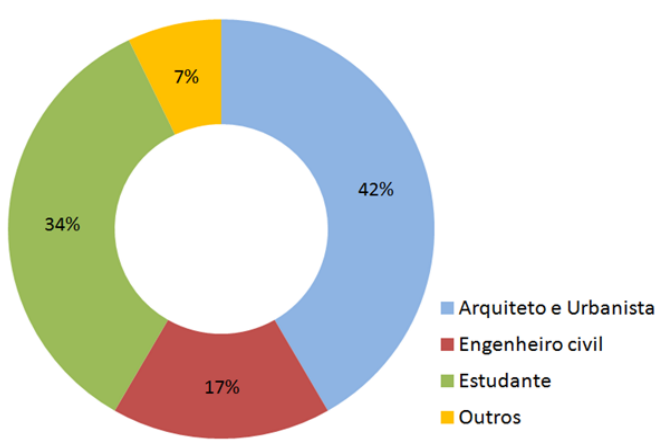

A
Quantos anos de formado?

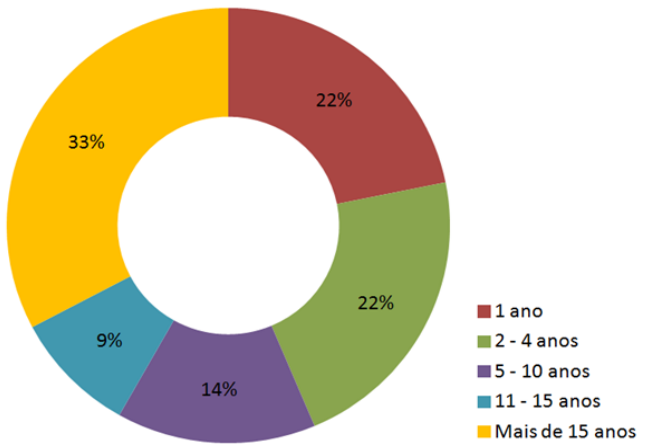

B

Fonte: Acervo dos autores.

Também foi abordada a existência de colaboração entre profissionais no processo de modelagem de edificações pelos participantes graduados, isto é, que não são estudantes (Gráfico 3), informação que permite identificar em que medida o processo é colaborativo ou conduzido isoladamente. Observa-se que:

- A participação de outros arquitetos no processo de modelagem esteve presente em $57 \%$ das respostas, sendo mais predominante a participação de até três profissionais (53\%);

- O restante da amostra (43\%) alegou não trabalhar com outros arquitetos; em filtragem de dados, percebe-se uma distribuição muito parecida entre arquitetos (11 respostas) e engenheiros $(10)^{5}$.

- Majoritariamente (60\% e 62\%) não há participação de outros engenheiros e estagiários na modelagem. 
- $\quad 78 \%$ dos participantes que não trabalham com engenheiros na modelagem são arquitetos.

- $\quad 77 \%$ dos participantes que não têm estagiários são arquitetos.

- Dentre os 14 respondentes (20\% da amostra da questão) que alegaram modelar sem a colaboração de nenhum profissional, 9 são arquitetos, 3 são engenheiros e 3 se definem com outra formação.

Gráfico 3: Profissionais que trabalham na construção do modelo.

Quantos profissionais trabalham com você na construção do modelo BIM?

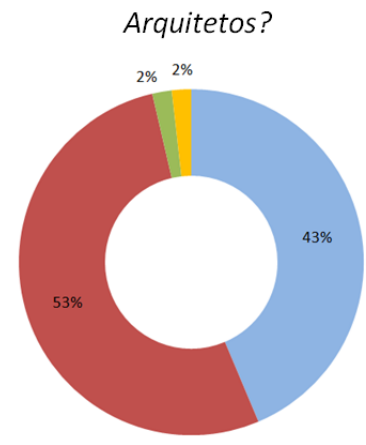

Nenhum

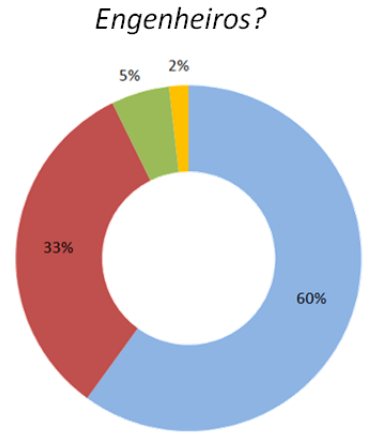

De 1 a 3
De 4 a 6

Fonte: Acervo dos autores.

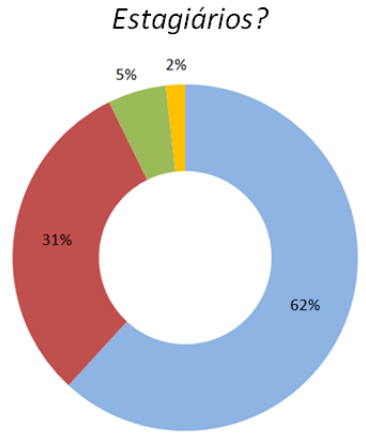

7 ou mais

A baixa colaboração entre os vários profissionais no mesmo modelo podem ter explicações diversas. A ausência de colaboração com engenheiros e estagiários, assim como a predominância de poucos arquitetos trabalhando em conjunto, sugerem a predominância de pequenos escritórios e profissionais autônomos, mas também podem ser sinal de uma implantação ainda parcial do processo BIM.

Os participantes também foram solicitados a marcar os tipos de projeto com que trabalham. Na questão foi fornecida uma lista de usos mais comuns e o respondente podia escolher dentre eles quantos itens considerasse necessário e, ainda, citar (por extenso) se houvesse algum outro tipo de projeto não contemplado (Gráfico 4). As respostas indicam maior ocorrência de projetos residenciais unifamiliares (43 respostas) e multifamiliares (34 respostas). Edificações comerciais de pequeno porte, reformas e projetos de arquitetura de interiores também são relativamente frequentes. Entre os arquitetos, verificou-se predominância de projetos residenciais unifamiliares (30 respostas), reformas (24 respostas), arquitetura de interiores (22 respostas) e habitação multifamiliar (21 respostas). Projetos residenciais também são frequentes entre engenheiros, assim como sua participação em projetos complementares.

Gráfico 4: Tipos de projeto mais recorrentes.

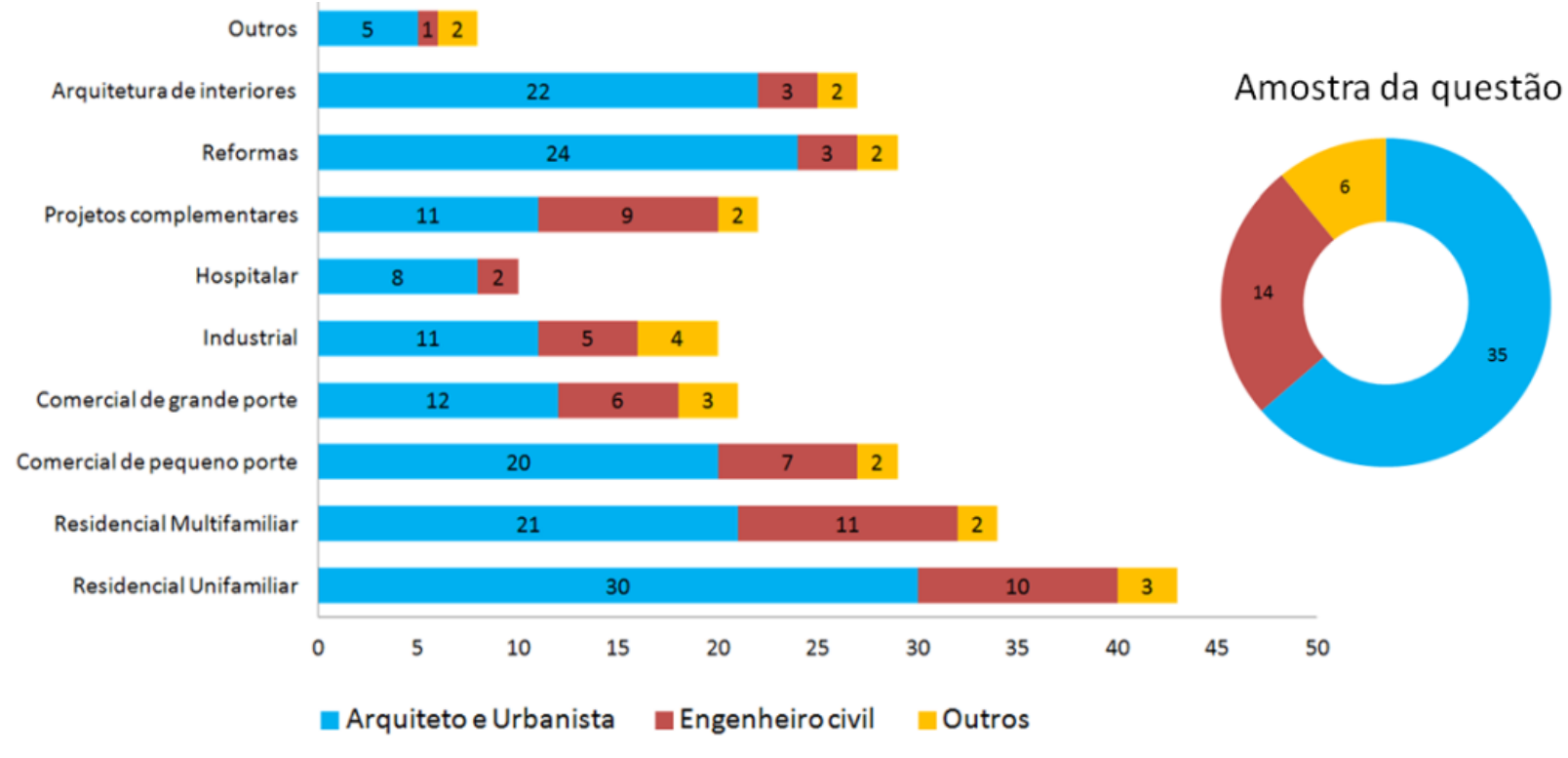

Fonte: Acervo dos autores. 
Também foi solicitado aos participantes que indicassem os papéis que desempenham no processo de modelagem BIM. A amostra da questão, por não considerar os estudantes ${ }^{6}$, é composta por 55 respondentes, sendo 35 arquitetos, 14 engenheiros e 6 profissionais de outras formações. A análise do material coletado (Gráfico 5) evidencia alguns pontos que merecem destaque:

- A atividade mais comum é a modelagem arquitetônica, indicada por quase todos os participantes (48);

- Duas atividades são bastante desempenhadas: produção de desenhos técnicos $2 \mathrm{~d}$, mais comum entre arquitetos, e modelagem estrutural, mais comum entre engenheiros;

- Cerca de um terço da amostra (19) cria famílias e objetos, que são partes que compõem o projeto (portas, janelas, corrimãos, dentre outros elementos construtivos).

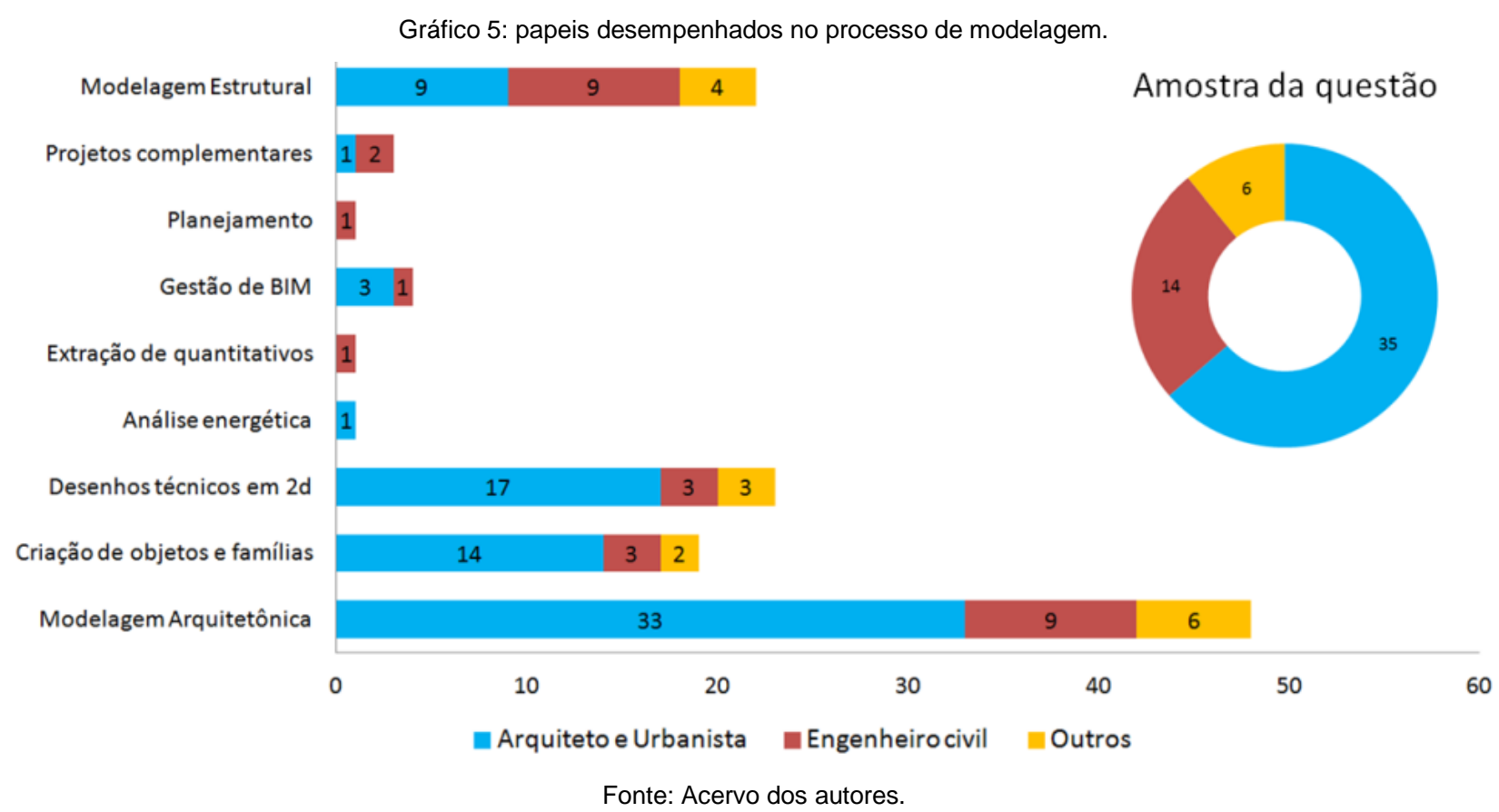

Para finalizar a caracterização inicial do grupo participante, os 84 respondentes selecionaram, dentre uma lista de ferramentas, quais delas são usadas em sua prática de projeto, sendo deixado um espaço para que citassem outros programas que não foram contemplados na listagem oferecida pela questão. No Gráfico 6 estão presentes os seguintes tipos de programas: ferramentas BIM (ArchiCAD, Allplan e Revit), programas que tratam de aspectos específicos do projeto (Eberick, Dalux, TQS, Robot, Tekla e CYPE Arquimedes), softwares de checagem de conflitos/compatibilização (Solibri, Navisworks, QI Builder) e outras ferramentas que podem ser usadas no processo, mas não são parte de ferramentas BIM (AutoCAD, SketchUp, Lumion, 3DS Max, Rhinoceros3d, Grasshopper, Dynamo). Os seguintes pontos merecem destaque:

- A ferramenta mais comum em todas as amostras é o Revit, indicada por $84 \%$ dos respondentes;

- Ainda há considerável ocorrência do AutoCAD (com ocorrência de quase $80 \%$ entre estudantes e $50 \%$ dos arquitetos);

- O SketchUp (programa de modelagem tridimensional simplificada, que trabalha exclusivamente com polígonos) é a terceira ferramenta mais adotada entre arquitetos e estudantes;

- Além do Revit, os engenheiros participantes selecionaram o AutoCAD e o Navisworks como ferramentas mais recorrentes; 
Gráfico 6: Ferramentas usadas pelos participantes em sua prática projetual.

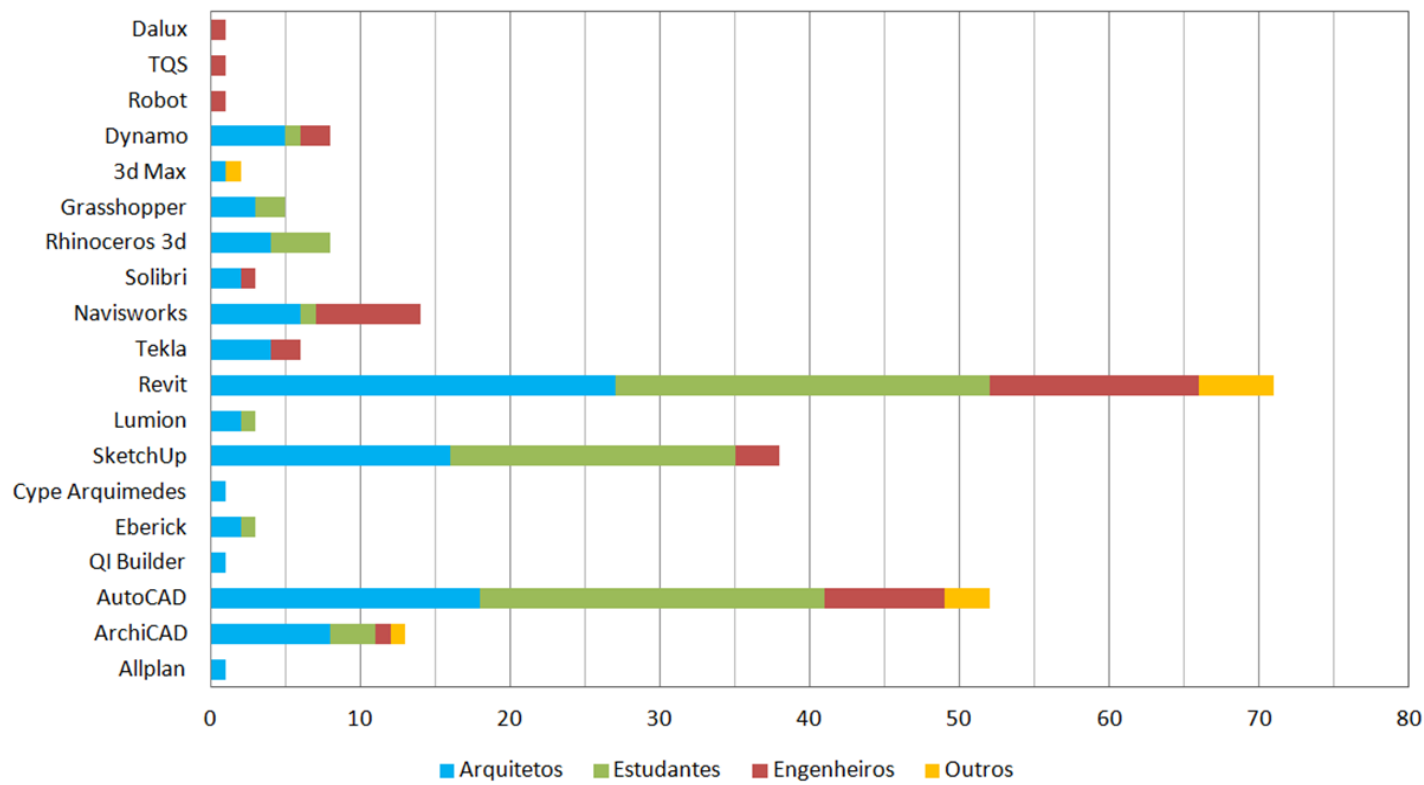

Fonte: Acervo dos autores.

\section{Prática de processos BIM}

Neste tópico, o questionário abordou questões referentes ao uso de ferramentas BIM ao longo do processo projetual. Essas informações caracterizam a abordagem dos respondentes em relação ao uso das ferramentas BIM.

A primeira questão busca identificar o nível de experiência do participante com modelagem BIM. Foram descritas as seguintes opções: iniciante (apresenta dificuldade em modelar elementos complexos ou específicos), experiência intermediária (consegue modelar alguns elementos, mas ainda apresenta dificuldade em outros) e muito experiente (consegue modelar qualquer elemento, apresentando mínima dificuldade). A análise dos resultados (Gráfico 7) indica que:

- Considerando a amostra total e as amostras parciais (de arquitetos, engenheiros, estudantes e outras formações), a maior ocorrência é de participantes com experiência intermediária em ferramenta BIM (48\% do total);

- A segunda maior amostra total (e entre arquitetos e engenheiros) é a de participantes muito experientes;

- A maior quantidade de participantes iniciantes é composta por estudantes.

Gráfico 7: Nível de experiência dos participantes.

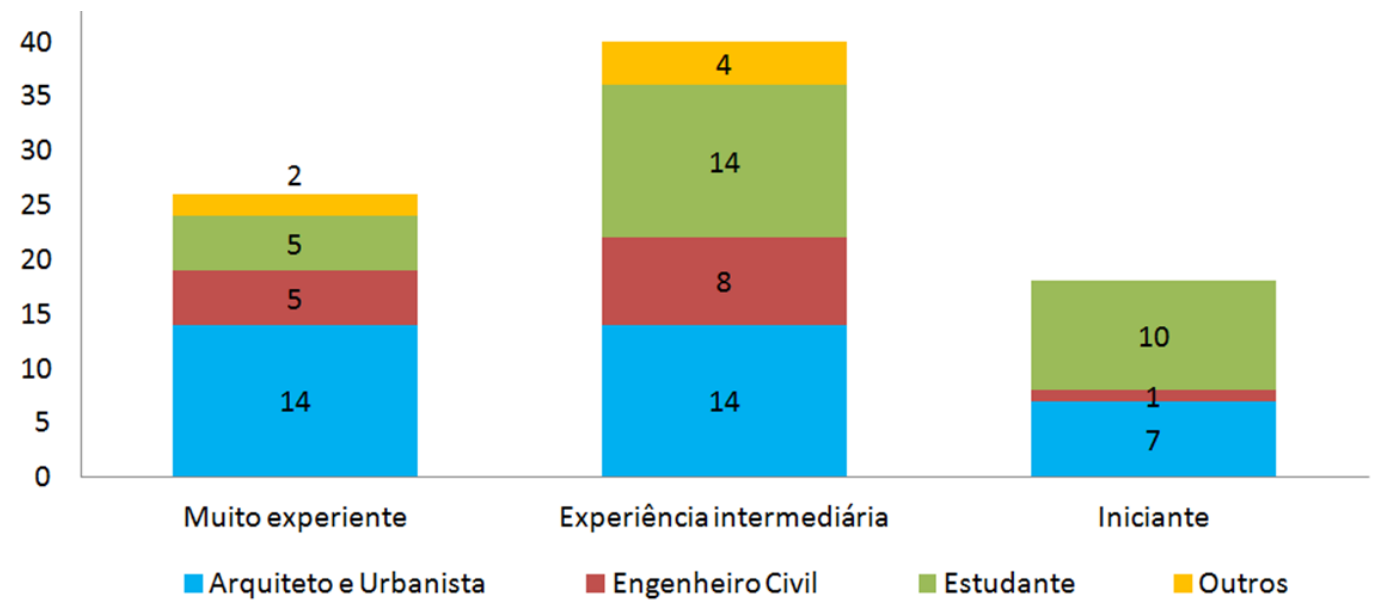

Fonte: Acervo dos autores. 
Informações sobre o nível de BIM adotado pelos usuários - em termos de informações e colaboração com outros profissionais - foi objeto de outra questão. Foram definidos quatro níveis de BIM:

- Nível1: O modelo BIM tem o objetivo de gerar desenhos ou representações em 3d. Não há uso de quantitativos nem colaboração com outros profissionais;

- Nível 2: Além de produzir os desenhos, o modelo BIM gera quantitativos de materiais e elementos usados no projeto. Não há colaboração de outros profissionais.

- Nível 3: Além de produzir desenhos e quantitativos, há colaboração de profissionais de outras áreas trabalhando no modelo.

- Nível 4: Além de produzir desenhos e quantitativos e de promover a colaboração com outros profissionais, o modelo BIM é usado para realizar pelo menos um tipo de análise/simulação de desempenho (planejamento de obra, análise energética, estrutura, dentre outros).

Os resultados (Gráfico 8) apontam que pouco mais da metade da amostra total não trabalha com processos colaborativos de modelagem (níveis 1 e 2), com grande predominância do uso de extração de quantitativos (níveis 2, 3 e 4).

Gráfico 8: Níveis de BIM que são adotados na prática de modelagem.

\section{Qual desses níveis de aplicação de processos BIM se aproxima mais de sua prática?}
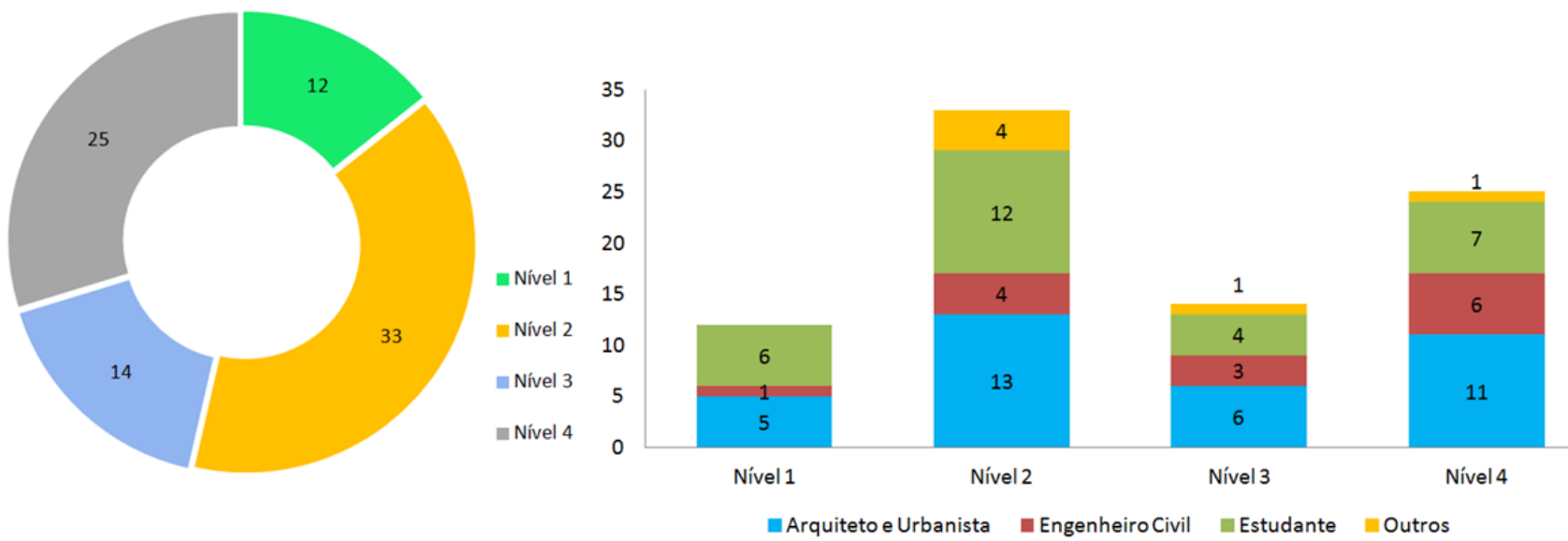

Fonte: Acervo dos autores.

Alguns outros pontos podem ser observados a partir da separação de subgrupos da amostra, conforme a formação (Gráfico 8):

- Metade dos participantes que usam ferramentas BIM apenas para gerar desenhos e representações (Nível 1) é composta por estudantes (6);

- O uso de quantitativos sem colaboração (nível 2) é predominantemente realizado por estudantes (12) e arquitetos (13).

- Considerando que os níveis 3 e 4 apresentam colaboração com outros profissionais, essa prática é realizada, ao todo, por quase metade dos arquitetos (17), boa parte dos engenheiros (9) e quase $40 \%$ dos estudantes (11).

Com relação às ferramentas usadas em três fases de projeto - estudo preliminar, anteprojeto e projeto executivo ${ }^{7}$ - a análise dos dados permitiu a identificação de alguns padrões (Gráfico 9):

- Há um grupo razoável de usuários que usa uma única ferramenta BIM desde as etapas iniciais do projeto: Revit (27 pessoas), ArchiCAD (5 pessoas) e Allplan (1 pessoa).

- Há também uma quantidade significativa de usuários que combinam uma ferramenta BIM com outros tipos de ferramentas (de modelagem, desenho, etc.) na etapa de estudo preliminar - 26 participantes se enquadram nessa categoria, combinando o uso desses programas com softwares de modelagem (SketchUp, Rhinoceros 3d) e de desenho técnico (AutoCAD).

- Uma terceira categoria, formada por 26 usuários, não usa nenhuma ferramenta BIM nas etapas iniciais do projeto. Nessa amostra, são recorrentes o uso do AutoCAD (7) e do SketchUp (7) isoladamente, assim como ambas as ferramentas combinadas (8). 
Gráfico 9: Quais ferramentas você utiliza em cada fase do projeto?

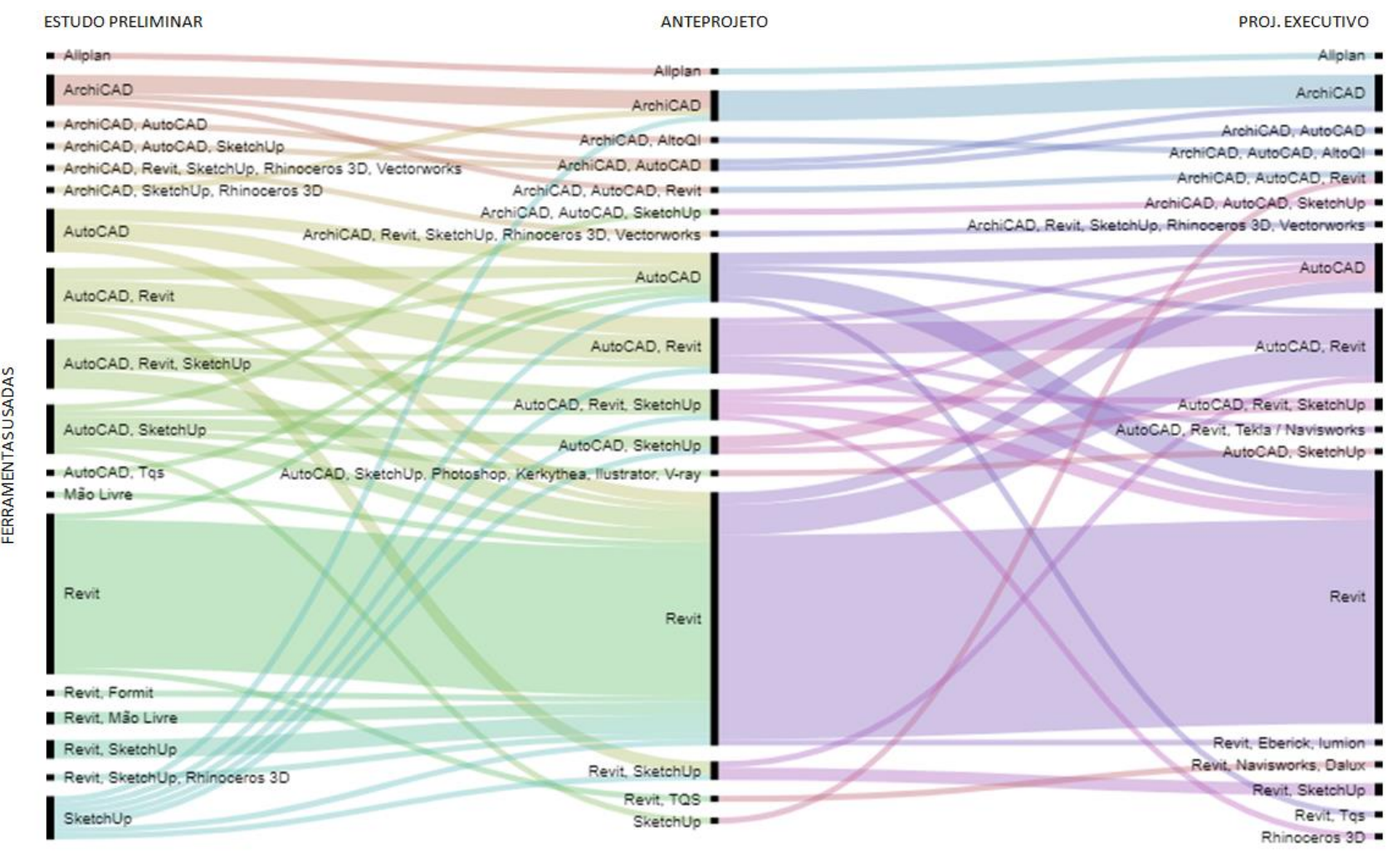

Fonte: Acervo dos autores.

Sabendo da possível dificuldade em lidar com a quantidade de informações requeridas pelos softwares BIM no início do projeto, os participantes foram solicitados a selecionar (ou indicar textualmente) que decisões de projeto já estão definidas antes do início da modelagem ou, ainda, explicar se tomam todas as decisões ao longo do uso da ferramenta $\mathrm{BIM}^{8}$. Para tanto, foram listadas várias definições de projeto e os participantes poderiam selecionar aquelas cuja definição antecede a modelagem BIM.

Os resultados foram filtrados de acordo com o nível de experiência dos participantes com ferramenta BIM (Gráfico 10) para facilitar a análise. Alguns pontos podem ser observados:

- Ao todo, as decisões de projeto que mais são tomadas antes de modelagem são: a organização espacial dos ambientes em planta (41), definição da forma da edificação (34), definição de níveis/patamares (33) e tipos de paredes (33).

- Decisões referentes às esquadrias (tipos e dimensões), definição do tipo de coberta e dos revestimentos foram selecionados por uma parcela menor da amostra total (entre 18 e $21 \%$ dos participantes).

- Pouco mais da metade da amostra de iniciantes define a forma (10) e organização espacial (13) antes de modelagem, assim como poucos iniciantes tomam todas as decisões durante o processo de modelagem (3).

- Os participantes com experiência intermediária com ferramentas BIM (maior amostra) selecionaram com maior frequência a definição de níveis/patamares (19), organização espacial em planta (18) e tipos de paredes (17); em nenhum dos casos houve maioria absoluta; decisões relacionadas às esquadrias, coberta e revestimentos são mais frequentemente tomadas por usuários com experiência intermediária durante a modelagem.

- Os participantes muito experientes selecionaram opções de forma mais distribuída, sem um padrão bem definido. Os itens mais selecionados pela amostra são: organização em planta (10), níveis/patamares (10), forma (9) e tipos de paredes (9). Ao todo, 8 participantes dessa amostra alegaram tomar todas as decisões durante a modelagem. 
Gráfico 10: Características do projeto que são definidas antes de iniciar a modelagem.

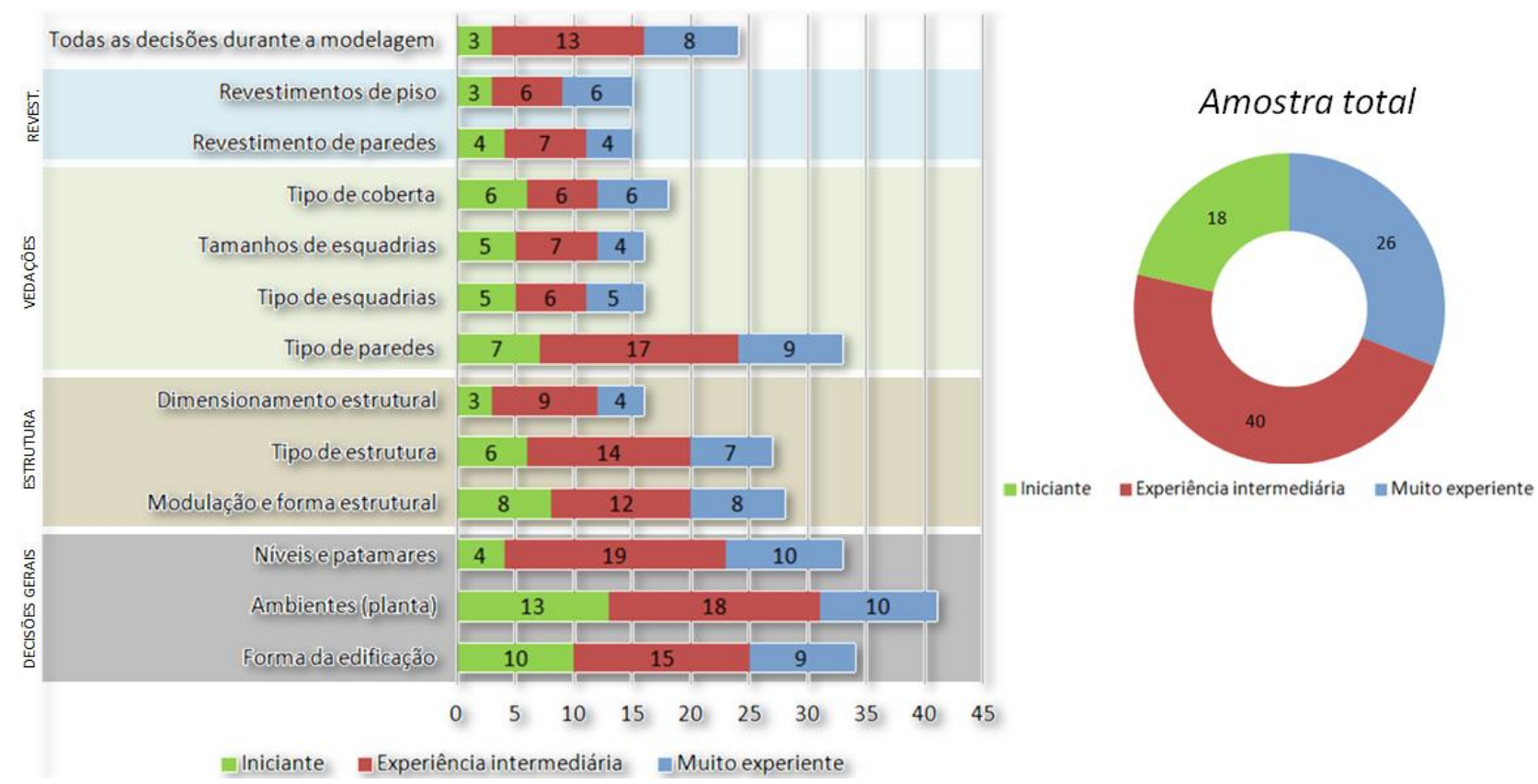

Fonte: Acervo dos autores.

Como o modelo BIM é uma representação isomórfica do objeto a ser construído (edificação), um dos desafios da modelagem é representar a especificidade das partes do projeto, que são modelos (objetos ou famílias $^{9}$ ) feitos à parte. Nesse campo, os participantes foram perguntados sobre a frequência com que modelam esses elementos. A análise dos resultados (Gráfico 11) indicam que:

- Quase metade da amostra total (46\%) desenvolve objetos específicos a cada projeto raramente (25) ou nunca (14);

- Cerca de $30 \%$ da amostra total desenvolve objetos específicos em mais de $50 \%$ dos projetos;

- $22 \%$ dos usuários da amostra total desenvolvem objetos específicos ocasionalmente;

- Metade da amostra de iniciantes (9) nunca modela esses objetos específicos, e um terço da amostra (6) modela raramente;

Gráfico 11: Frequência do desenvolvimento de famílias/objetos conforme a necessidade de cada projeto.

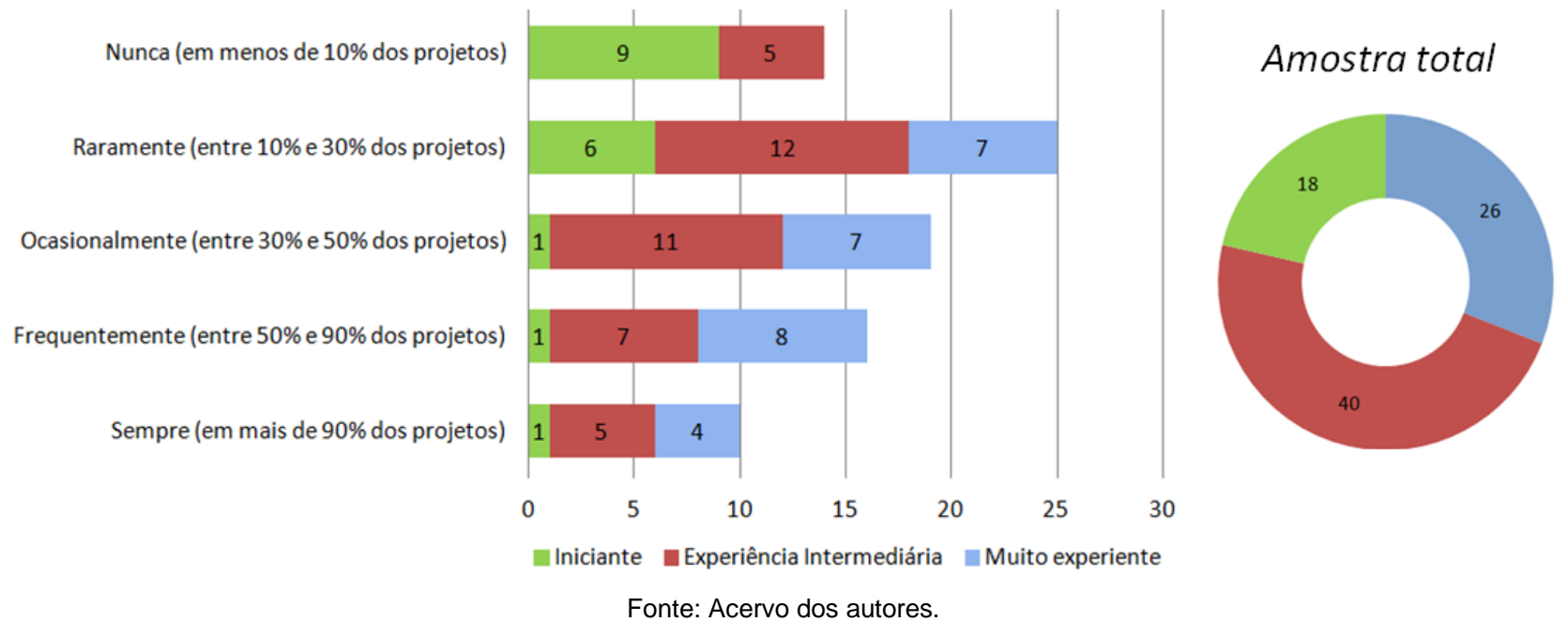

O nível de fidelidade da modelagem BIM também foi objeto de uma questão. Um modelo BIM pode ter diferentes graus de simplificação do modelo virtual em relação a uma construção real. Foram definidos pelos autores quatro níveis de fidelidade com nomenclatura própria para que cada usuário selecionasse um deles: 
- BAIXO: o modelo é simplificado e são feitas alterações em 2D para a produção de desenhos;

- MÉDIO: os dados quantitativos não são levados em conta e algumas simplificações são feitas na modelagem para tornar o modelo mais leve;

- ALTO: algumas simplificações são feitas na modelagem, mas sem prejudicar a extração de dados quantitativos;

- MUITO ALTO: a maior parte dos elementos é modelada como seria construída, levando em conta os dados quantitativos.

Quanto ao nível de fidelidade dos modelos BIM em relação à obra construída (Gráfico 12), algumas observações podem ser feitas:

- Mais da metade da amostra de iniciantes não trabalha com quantitativos, sendo que 8 participantes realizam modelos de modo simplificado, para gerar os desenhos;

- Dois terços da amostra total apresentam níveis de fidelidade alta (23) ou muito alta (23);

Gráfico 12: Nível de fidelidade da modelagem.

\section{Qual o nivel de fidelidade do modelo BIM?}
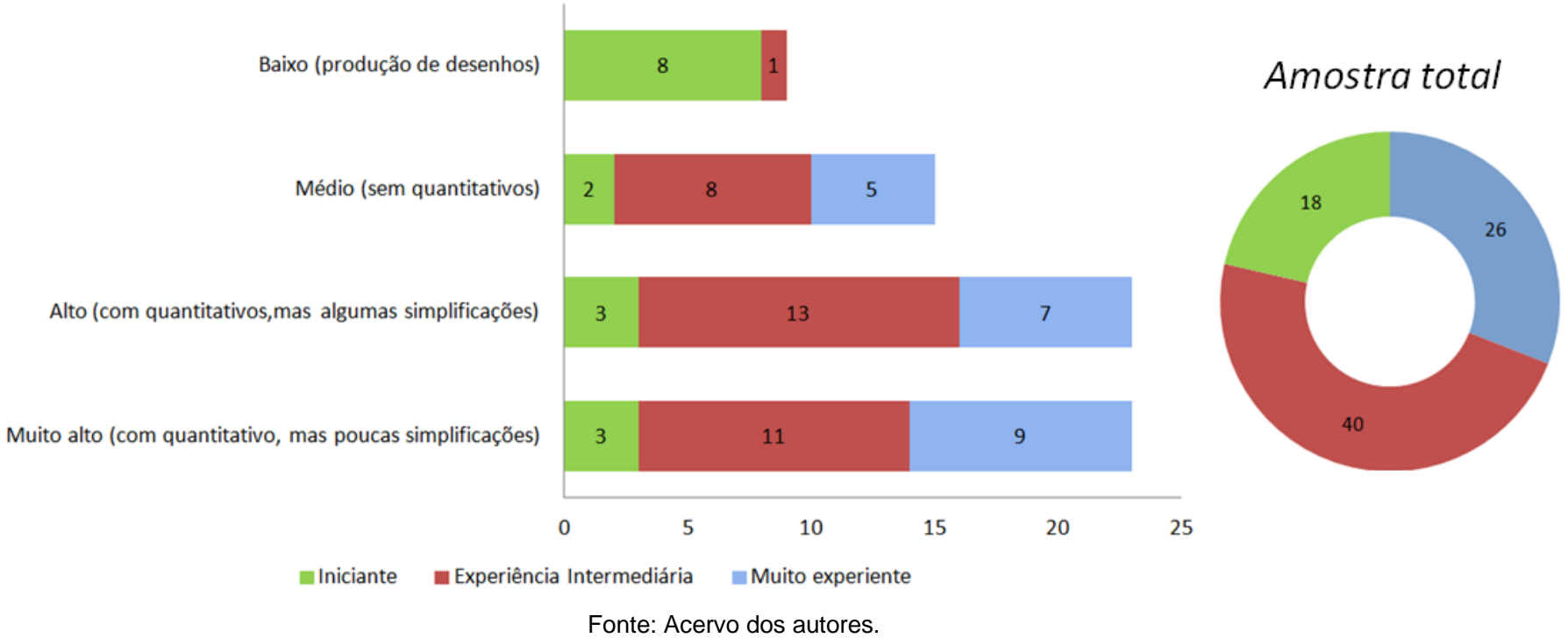

Os participantes também foram solicitados a indicar o percentual de tempo gasto em algumas das atividades principais de processos de modelagem BIM. Nessa questão foram desconsideradas as respostas cujo somatório das porcentagens extrapolou o limite de $120 \%{ }^{10}$. Os dados obtidos tornam possível observar algumas tendências (Gráfico 13):

- A atividade que mais consome tempo é a modelagem (em média, $41 \%$ do tempo);

- Os usuários passam menos tempo para a criação de bibliotecas e famílias (em média, 10\% do tempo);

- Algumas atividades como a checagem de erros no modelo e a produção dos desenhos $2 \mathrm{~d}$ levam, segundo a média dos resultados, mais tempo do que a criação de objetos e famílias. 
Gráfico 13: Porcentagem de tempo média utilizada em cada atividade na elaboração do modelo BIM.

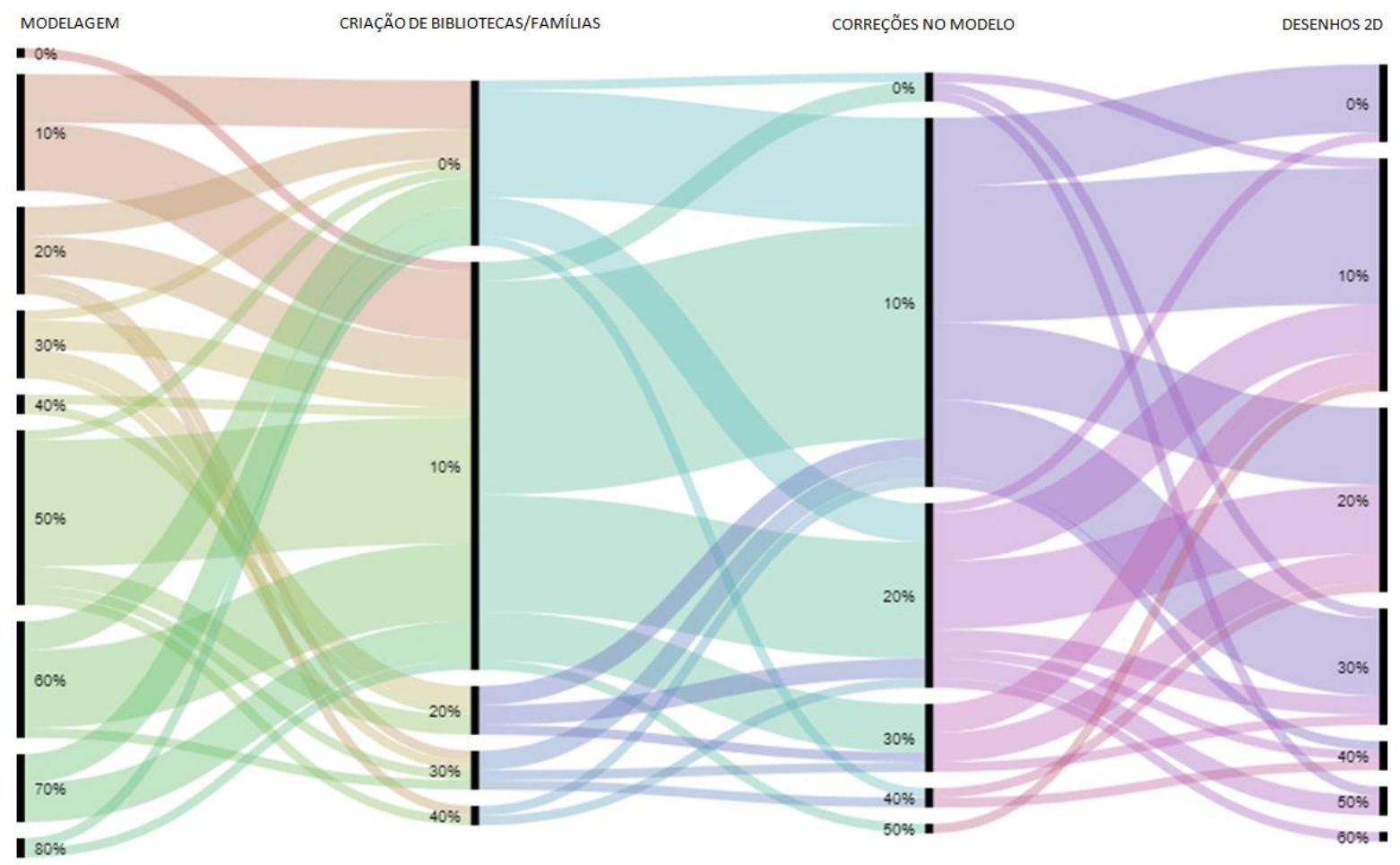

Fonte: Acervo dos autores.

\section{SÍNTESE: LIGANDO OS PONTOS}

Os dados analisados permitem a identificação de alguns fenômenos que sintetizam algumas das principais descobertas da pesquisa, fazendo relação entre as respostas obtidas e o contexto mais amplo do projeto e ensino de arquitetura. Nesta seção, serão apresentados alguns tópicos que buscam trazer à tona os principais rebatimentos dos resultados na prática projetual.

\section{0 problema de ser um iniciante}

Ferramentas BIM devem permitir a modelagem de uma construção. Por essa razão, envolvem procedimentos complexos e uma curva de aprendizado íngreme. Contudo, a complexidade de um programa não necessariamente tem um rebatimento tão direto na qualidade do produto final. Percebe-se que isso ocorre, por exemplo, na maioria das ferramentas CAD de desenho técnico. Há programas extremamente complexos, como o próprio AutoCAD, que apresentam grande quantidade de recursos. Mesmo assim, na prática em sala de aula, observa-se que é possível que alunos produzam bons desenhos técnicos com um conhecimento bastante limitado dos recursos disponíveis. Isso ocorre por duas razões:

- Simplicidade das informações: um desenho técnico envolve informações de natureza geométrica (linhas, arcos, etc.) e textual;

- Flexibilidade: existem muitas maneiras de se fazer uma mesma tarefa - ainda que em níveis diferentes de eficiência.

Quando se fala em ferramentas BIM, o mesmo não ocorre. A falta de proficiência no programa tem relação direta com a qualidade do modelo ou com as possibilidades de aplicação do processo BIM. Os resultados apontam que os iniciantes (que têm dificuldade em modelar elementos mais específicos) apresentam uma série de limitações em seus fluxos de trabalho.

A primeira delas diz respeito à aparente dificuldade em lidar com um programa que requer grande quantidade de informações. No início do processo projetual, a maior parte dos iniciantes usa outros tipos de programa (de desenho ou modelagem) ou combinam esses programas com uma ferramenta BIM. $O$ interessante é que a adoção de ferramentas BIM em fases iniciais do projeto não necessariamente é mais difícil do ponto de vista operacional (do programa), já que essas informações podem ser criadas de modo simplificado para serem refinadas em etapas posteriores - que é a essência do conceito de Level of Development, proposto pelo American Institute of Architects (2008). 
O Gráfico 14 mostra que a maior parte dos iniciantes não usa ferramenta BIM nas fases de estudo preliminar (marcação em azul) e apenas uma pequena parcela adota um programa de modelagem BIM isoladamente (parcela indicada em vermelho no gráfico).

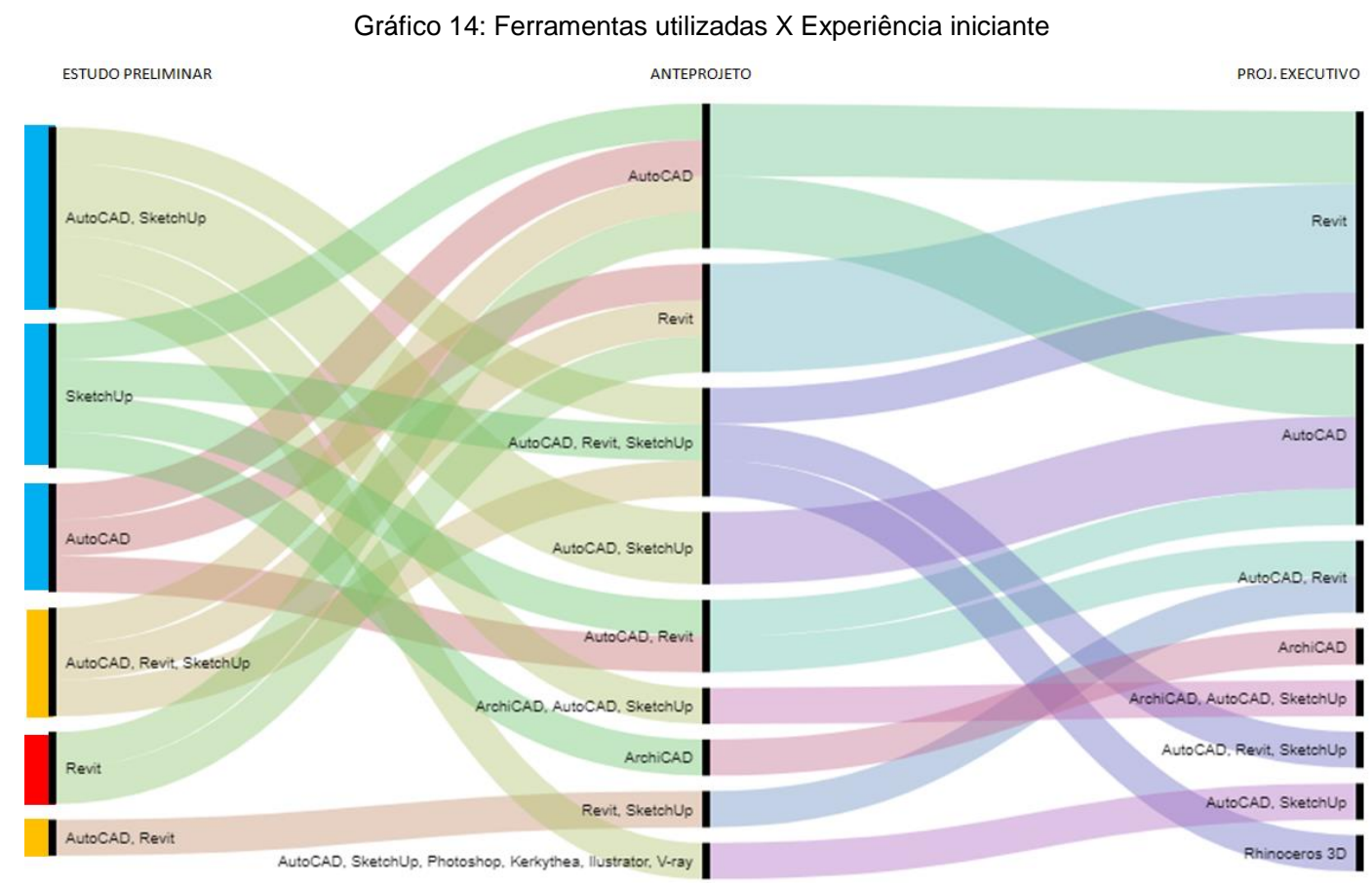

Fonte: Acervo dos autores.

Os resultados indicaram que, quando iniciantes usam ferramentas BIM, os modelos tendem a ser menos fiéis à construção e que, devido à dificuldade em modelar elementos específicos, há uma baixa ocorrência de modelagem de objetos e famílias - elementos essenciais para marcar a especificidade das partes de qualquer projeto.

Assim, o iniciante em ferramenta BIM apresenta deficiências que irão afetar não somente a qualidade do modelo final, mas limitar seu processo decisório e afetar a qualidade do projeto. A falta de proficiência pode levar o iniciante à supersimplificação do projeto para que o modelo seja condizente com seu nível de conhecimento prático no programa. Dessa forma, se o usuário não domina o programa, pode ser facilmente dominado por ele.

Certamente as limitações do iniciante tendem a ser passageiras na medida em que o usuário aprende novos recursos na operação do programa. Contudo, é possível que, mesmo com o amadurecimento na ferramenta, ainda perdurem algumas práticas viciosas adquiridas ao longo do aprendizado. Essa possibilidade talvez seja mais provável de acontecer com estudantes, que ainda se encontram em fase de formação de seu repertório de ações projetuais.

Para verificar se há algum indício desse risco, filtramos as respostas de estudantes com níveis de experiência intermediária e avançada. Essa amostra tem 19 participantes, sendo 14 com experiência intermediária e o restante da amostra com experiência avançada.

Ainda que a amostra não seja numerosa, os resultados (Gráfico 15) sugerem que esses estudantes tendem a ter modelos de alta fidelidade em relação ao objeto construído (15, somando níveis de fidelidade "alto" e "muito alto"). Contudo, ainda se verifica que um terço dos estudantes (7, somando as categorias "Raramente" e "Nunca") não têm o costume de criar novas famílias para as partes dos seus projetos. Assim, podemos até ter modelos que são fiéis à construção real, mas cujas partes se limitam aos objetos e famílias extraídos de sites e comunidades virtuais. Com enfoque na formação em processos BIM, Mandar e Mandhar (2013) abordam alguns dos dilemas na implementação dessa tecnologia no ensino de graduação. Os autores fazem a contraposição entre ensinar um programa específico e ensinar a tecnologia por trás do processo BIM. O que parece haver no contexto desta pesquisa é uma formação centrada na ferramenta e que pode comprometer o processo de concepção. 
Gráfico 15: Prática de estudantes com experiência intermediária e avançada em ferramentas BIM.

Nível de fidelidade do modelo

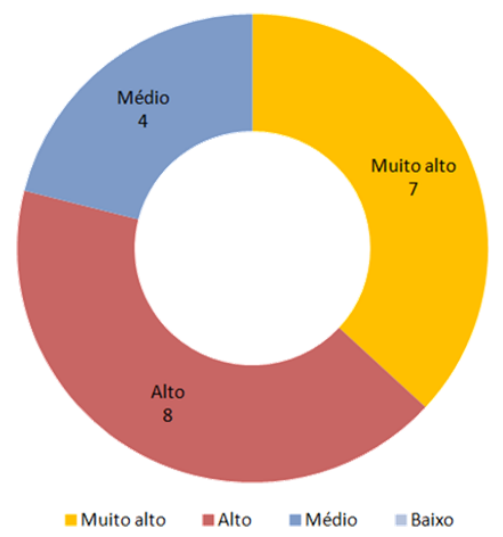

Com que frequência modelam famílias/objetos

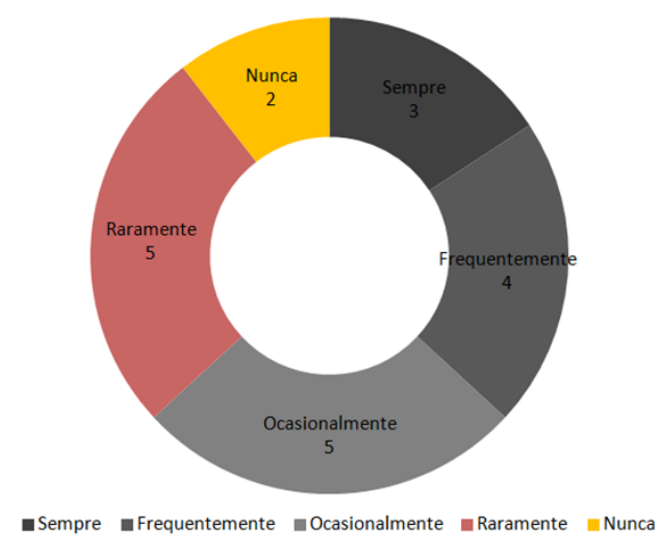

Fonte: Acervo dos autores.

\section{Um novo tipo de precedente projetual}

A pesquisa de precedentes de projeto (projetos completos ou partes de projeto semelhantes ao que está em desenvolvimento) é uma prática inerente à atividade projetual. Nestas investigações, os projetistas procuram identificar soluções já testadas e que podem ser traduzidas e reutilizadas em futuras soluções, através de analogias. Esse mecanismo, em projetos arquitetônicos, pode ter várias motivações, tratando desde aspectos pragmáticos de natureza técnica até de aspectos formais ou simbólicos.

O uso de analogias no projeto é um atalho para resolver problemas. É um processo particularmente útil para abordar problemas não familiares, sobretudo quando não há conhecimento que possa ser diretamente aplicado (GERO, MAHER, 1991). O 'pensamento analógico' envolve a transferência de conhecimento anterior de uma situação familiar (fonte), para uma situação não familiar (alvo), que precisa ser elucidada. Naturalmente, isso ocorre na mente do arquiteto e é demasiado complexo para ser descrito objetivamente ${ }^{11}$.

Os resultados obtidos indicam que, na maior parte do tempo, as partes do projeto não estão sendo pensadas como elementos específicos ( $46 \%$ da amostra total raramente cria esses elementos). $O$ compartilhamento de partes de projetos é tão comum que os dados obtidos indicaram que a modelagem e criação desses elementos (objetos e famílias) é a atividade que consome menor quantidade de tempo dentre as opções listadas (em média 10\% do tempo). Atualmente há grande variedade de websites e comunidades virtuais que facilitam o compartilhamento desses modelos.

Ao contrário dos blocos de AutoCAD construídos de modo tradicional, objetos de um modelo BIM apresentam informações (geometria, tipo, materiais, etc.) que os tornam únicos. A natureza antiabstrata desses objetos, inclusive, faz com que alguns desses elementos sejam mais do que blocos. São, na verdade, soluções de projeto.

A facilidade em 'baixar' modelos existentes e o conhecimento e esforço necessários para criar modelos próprios tem rebatimento direto no projeto. Há uma tendência de restringir a atuação do arquiteto na definição de partes específicas do projeto. O usuário pode, por exemplo, deixar de pensar nos elementos que poderiam ser únicos no projeto, para concentrar seus esforços na procura por objetos existentes que 0 agradam. O modo de conceber muda completamente. Em vez de conceber e modelar um tipo de corrimão que seja adequado para determinado projeto específico, o arquiteto vai procurar, dentre um universo limitado de opções, qual corrimão the agrada mais.

\section{Antecipando decisões de projeto}

É comum em fases iniciais de projeto que as primeiras ideias sejam mais abstratas. Não temos capacidade mental de conceber o todo e suas partes em um mesmo momento. Então, ainda que seja possível já ter noção sobre algumas definições de detalhes específicos, não seria absurdo afirmar que, no início do projeto, a tendência é que as definições digam respeito a aspectos gerais do projeto (implantação, organização espacial, forma, etc.). 
Em processos de projeto que adotam ferramentas BIM, alguns usuários podem se sentir compelidos a antecipar algumas decisões para se assegurar que o modelo fique bem organizado desde o início.

Um exemplo de uma decisão que pode ser antecipada envolve os revestimentos de paredes. Uma parede de alvenaria comum, num programa BIM, é composta por camadas de materiais. O tijolo forma o núcleo da parede e camadas de revestimento dão o acabamento necessário. Os pilares e vigas (supondo uma estrutura de concreto armado) normalmente estão alinhados ao núcleo da parede, não à face externa do revestimento. Ainda que, em fases iniciais, possamos usar uma parede genérica, formada por uma única camada sem material definido, e facilmente trocá-la pela parede específica que vamos usar, essa simples necessidade de alinhamento entre estrutura e vedações pode fazer com que algumas pessoas se sintam forçadas a definir os tipos de parede e revestimentos para evitar retrabalhos ou um modelo desorganizado.

Os resultados apontam que 25 participantes (30\% da amostra) definem os revestimentos de paredes ou pisos antes de iniciar a modelagem. Grande parte dessa amostra (19) usa ferramenta BIM desde o estudo preliminar, o que sugere que provavelmente estão realmente antecipando essas decisões para inseri-las no modelo desde o início. $O$ uso de paredes genéricas não é feito por 33 participantes, que alegaram definir o tipo de parede antes da modelagem, assim como 26 usuários definem alguma propriedade das esquadrias (tipo ou tamanho).

A dificuldade em trabalhar com modelos mais abstratos em fases iniciais foi destacada por alguns participantes nas questões discursivas, como se pode observar nas transcrições a seguir, extraídas dos questionários e relacionadas às dificuldades no uso de ferramenta BIM:

- "Tornar a modelagem simples e rápida suficiente para um momento de anteprojeto e estudo de massas e áreas".

- "Às vezes a ferramenta tem parâmetros que limitam o desenvolvimento impedindo o desenvolvimento de formas mais livres e de forma mais intuitiva".

- "Necessidade de configuração de praticamente todos os elementos de uma vez".

Em diversas situações, a antecipação de muitas definições de projeto pode apresentar risco de prejudicar a desejável maleabilidade do projeto em fases iniciais e atrapalhar os esforços de projeto para as definições gerais nas primeiras etapas de projeto. Não por acaso, a maioria da amostra (51) não faz uso exclusivo de ferramenta BIM nas etapas iniciais do projeto, mas sim em combinação com outros programas.

O Gráfico 16 indica que alguns usuários que combinam o uso de ferramentas BIM com outros tipos de programas na fase de estudo preliminar (indicações amarelas) passam a adotar exclusivamente uma ferramenta BIM na etapa subsequente (indicações vermelhas). A maioria, contudo, continua realizando algum tipo de combinação entre ferramentas e alguns usuários irão usar ferramentas BIM apenas depois do anteprojeto.

Gráfico 17: Usuários que não usam ferramentas BIM isoladamente nas fases iniciais de projeto.

ANTEPROJETO

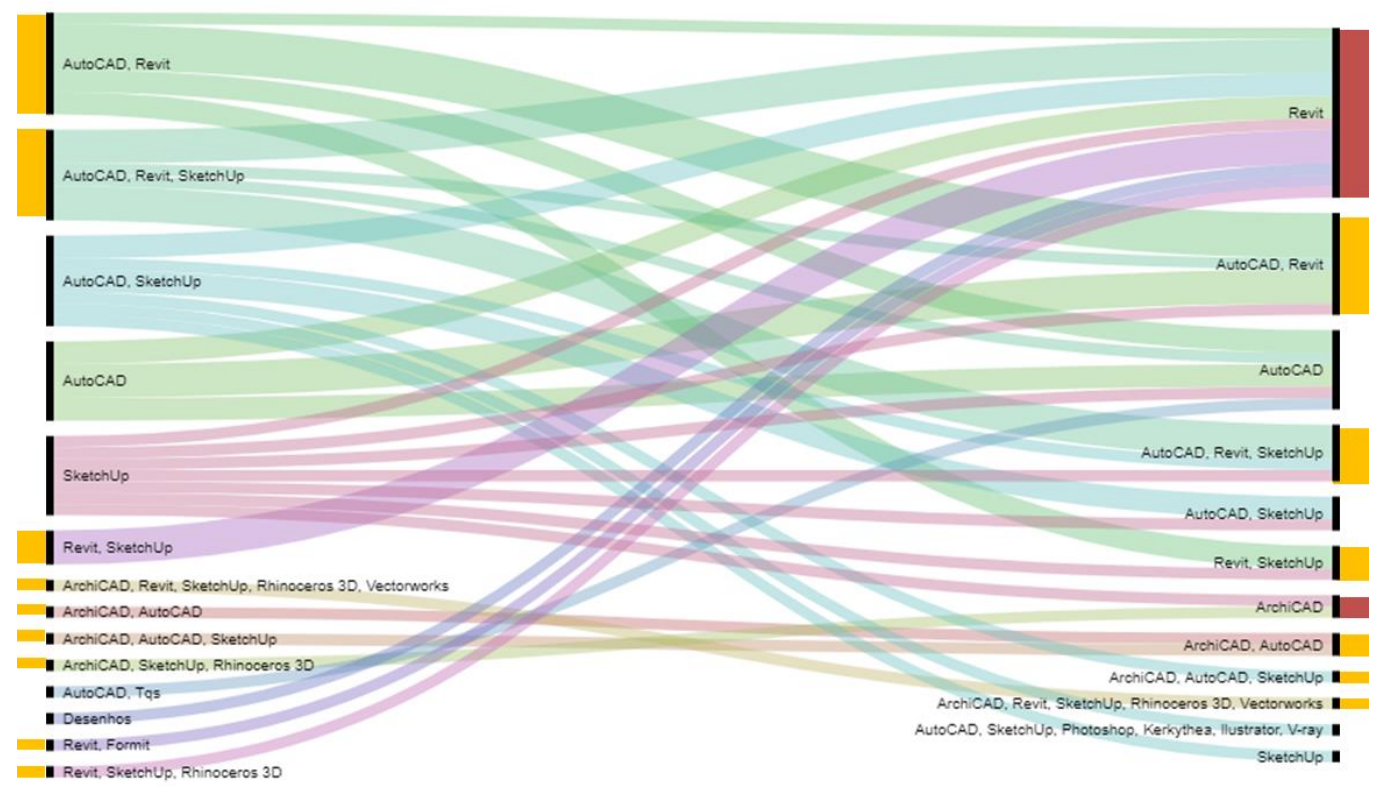

Fonte: Acervo dos autores. 
O conceito de enquadramento de situações de projeto (SCHÖN, 1985) é também motivado por não conseguirmos lidar com todos os problemas de uma vez. Precisamos eventualmente isolar determinados aspectos em detrimento de outros. Esse processo é descrito pelo autor através do diálogo entre um professor e uma aluna, que refletem sobre a implantação de determinado projeto. Esse processo de reflexão, com o uso do desenho manual é suficientemente fluido, pois as informações inseridas são abstratas e há como isolar, ressaltar ou suprimir informações com facilidade.

Nossos resultados sugerem que, no desenvolvimento de um modelo BIM, parte considerável da amostra parece antecipar algumas definições de projeto para supostamente ter maior controle sobre o modelo.

\section{CONCLUSÃO}

Este trabalho apresenta os resultados da aplicação de questionário online que investigou fluxos de trabalho com ferramentas BIM. A análise dos resultados se vale da aplicação de filtros de dados, o que permite caracterizar não somente a amostra total, mas vários recortes da mesma, de modo a compreender melhor os problemas abordados no questionário.

A análise dos dados, de natureza descritiva, leva à síntese dos resultados, baseada em interpretações de informações objetivas. Nessa etapa, foram identificados alguns dos principais fenômenos presentes nas respostas que podem ter rebatimento direto na prática de projeto. Para evitar a ocorrência dos problemas mencionados, é necessário que o treinamento em ferramentas BIM leve em conta mais do que a mera execução de comandos, mas aborde o uso da ferramenta e seu potencial em todas as fases de projeto.

O método de pesquisa, embora permita um alcance considerável em todo o território nacional, tem a limitação de não permitir ao pesquisador averiguar a fidelidade das respostas ou confrontar os respondentes com eventuais conflitos em respostas complementares. Trabalhos futuros podem se concentrar nas práticas de usuários iniciantes nas ferramentas e suprir essas limitações com aplicação de outros procedimentos metodológicos como entrevistas e acompanhamento de processos projetuais em ambiente acadêmico.

\section{REFERÊNCIAS}

AMBROSE, M. A. Plan is dead: to BIM or not to BIM, that is the question. ARAB SOCIETY FOR COMPUTER AIDED DESIGN (ASCAAD 2006). Proceedings of ASCAAD 2006. Sharjaj, Emirados Árabes. ASCAAD, 2006, pp. $182-189$

AMERICAN INSTITUTE OF ARCHITECTS. E202: BIM Protocol Exhibit. Washington: AIA. 2008.

BECERIK-GERBE, B.; RICE, S. The Perceived Value of Building Information Modeling in the U.S. Building Industry. Journal of Information Technology in Construction, vol.15, 2010, pp. $185-201$.

BRYDE, D.; BROQUETAS, M.; VOLM, J. M. The project benefits of Building Information Modelling (BIM). International Journal of Project Management, v. 31, n. 7, p. 971-980, 2013.

DONN, M. Simulation of Imagined Realities: environmental design decision support tools in architecture. 2004. (PhD). Victoria University, Wellington, NZ.

FERNANDES, R. P. L. Advantages and Disadvantages of BIM Platforms on Construction Site. Disssertação de Mestrado. Departamento de Engenharia Civil, Universidade do Porto, Porto, Portugal, 2013.

GERO, J. S.; MAHER, M. L. Mutation and analogy to support creativity in computer-aided design. In: SCHMITT, G. N. (Ed.). CAAD futures 91'. Zurich: ETH, 1991, pp. 01 - 09.

MANDHAR, M.; MANDHAR, M. BIMing the architectural curricula: Integrating Building Information Modelling (BIM) in Architectural Education. International Journal of Architecture, v. 1, n. 1, p. 1-20, 2013.

RAMOS, F. G. V. O desenho e a arquitetura em Leon Battista Alberti e Giorgio Vasari. VII Encontro de história da arte. Anais do VII Encontro de História da Arte. Campinas, SP: UNICAMP, 2011, pp. 535 - 544.

SCHÖN, D. The design studio: an exploration of its tradition and potentials. London: RIBA Publications Limited, 1985.

SCHÖN, D. A. The reflective practitioner: How professionals think in action. London: Temple Smith, 1983.

TAKIM, R.; HARRIS, M.; NAWAWI, A. H. Building Information Modeling (BIM): A new paradigm for quality of life within Architectural, Engineering and Construction (AEC) industry. Procedia - Social and Behavioral Sciences, v. 101, n. 8, p. 23-32, 2013.

TALEBI, S. Exploring advantages and challenges of adaptation and implementation of BIM in project life cycle. 2nd BIM International Conference on Challenges to Overcome. Proceedings of $2^{\text {nd }}$ BIM International Conference. Lisboa, Portugal 2014.

YAN, H.; DAMIAN, P. Benefits and Barriers of Building Information Modelling. 12th International Conference on Computing in Civil and Building Engineering (ICCCBE XII). Proceedings of ICCCBE XII. Pequim, China: Tingshua University Press, 2008, pp. 294-300. 


\section{NOTAS}

${ }^{1}$ Esse processo de enquadramento da situação de projeto é também descrito por Schön (1983).

$2 \mathrm{O}$ desenho não é completamente o fim do processo, pois boa parte do modelo de informação é modelada com procedimentos parecidos com o de desenho assistido por computador (através de vistas ortogonais); a maior diferença é que os elementos desenhados têm informações embutidas (altura, camadas de materiais, aparência de revestimentos, etc.).

${ }^{3}$ Existem certas divergências conceituais entre autores diferentes, mas a ideia comum a todos os modelos é a tentativa de traduzir a gradual evolução do projeto com a adição de informações (geométricas e de outras naturezas) ao longo do processo projetual.

${ }^{4}$ As ocorrências denominadas "outros" se referem a participantes de outro tipo de formação (tecnólogo, designer, etc.).

${ }^{5}$ Além de arquitetos e engenheiros, 3 participantes com outras formações também alegaram não trabalhar com outros arquitetos no processo de modelagem.

${ }^{6}$ Como estudantes lidam com projetos compreendidos num curto intervalo de tempo, é natural que não desempenhem as mesmas atividades de um processo de projeto profissional e enfoquem mais a modelagem e representação do objeto.

${ }^{7}$ Essa nomenclatura foi escolhida para caracterizar as fases projetuais por serem termos vastamente adotados na prática brasileira.

${ }^{8} \mathrm{~A}$ opção "tomo todas as decisões durante o processo de modelagem" é exclusiva, pois se entende que elimina a necessidade de se tomar decisões antes do processo de modelagem.

${ }^{9}$ Terminologia usada no programa mais adotado pela amostra, o Revit.

${ }^{10}$ Talvez por uma interpretação equivocada, algumas respostas somaram mais de $200 \%$ e tiveram que ser desconsideradas da análise da questão. Um excedente pequeno (até $20 \%$ ) poderia ser fruto de um erro no somatório, mais do que na leitura da questão.

NOTA DO EDITOR (*) O conteúdo do artigo e as imagens nele publicadas são de responsabilidade do(s) autor(es). 